\title{
Assessment and Treatment of Systemic Right Ventricular Dyssynchrony
}

\author{
Tomoko Ishizu, MD, PhD; Hitoshi Horigome, MD, PhD
}

ardiac resynchronization therapy (CRT) for patients with congenital heart disease is a promising therapeutic option as shown in the report by Sakaguchi et $\mathrm{al}^{1}$ in this issue of the Journal. In their study, the clinical response to CRT was compared among systolic ventricular anatomical morphologies: systemic left ventricle, systolic right ventricle, and single ventricle (Figure 1). The results from the single center, which is one of the most experienced, highvolume institutes in Japan, showed CRT benefit in patients with systemic left or single ventricular morphology. However, 7 patients with systemic right ventricle (RV) did not achieve apparent 6-month response from CRT, showing no effect on
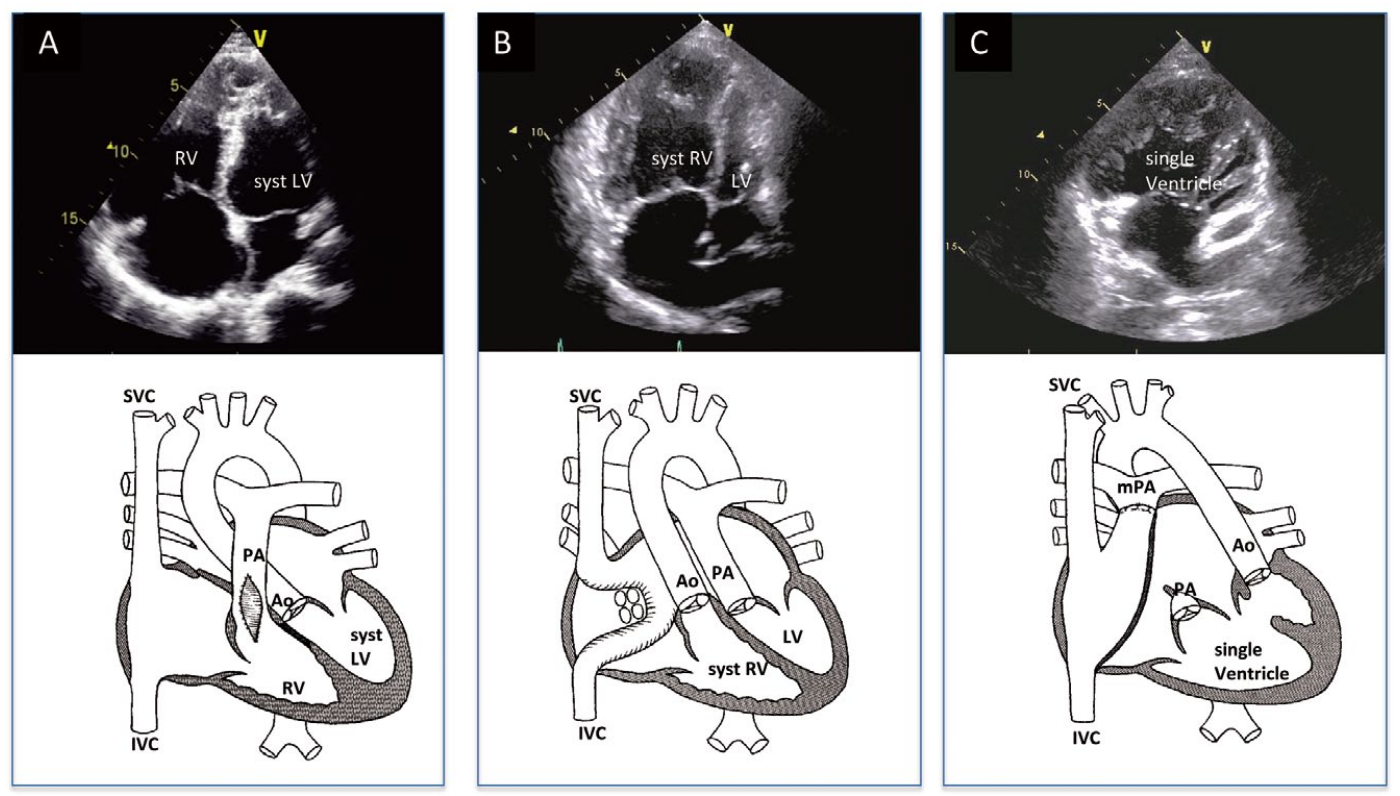

Figure 1. Congenital heart disease anatomical subgroups after surgical repair. (A) Example of a syst LV. Repair of tetralogy of Fallot with patch closure of a ventricular septal defect and a right ventricular (RV) outflow/main PA outflow patch. The left ventricle is the systemic ventricle. The right ventricle is dilated because of pulmonary regurgitation. In tetralogy of Fallot, systemic left ventricular failure may develop. (B) Example of syst RV. Venous switch echocardiogram shows the apical 4-chamber view after the Senning procedure in a patient with transposition of great arteries. Mustard repair is another atrial switch operation explained in the schematic. The morphological right ventricle is the systemic ventricle in patients with transposition of great arteries undergoing an atrial switch operation. Systemic RV failure may develop in one-third of cases of congenital/surgical corrected transposition of great arteries. (C) Example of a single ventricle. Apical view of RV morphology with hypoplastic left ventricle. The diagram shows an example of Fontan repair for single ventricular morphology, right atrial to PA anastomosis with atrial "baffle" and ligation of proximal PA for ventricular inversion, transposition of great arteries, double-inlet ventricle, and hypoplastic subaortic outlet chamber. The failure of the single ventricle is common in patients with a hypoplastic left ventricle. IVC, inferior vena cava; PA, pulmonary artery; SVC, superior vena cava; syst LV, systemic left ventricle; syst RV, systemic right ventricle.

The opinions expressed in this article are not necessarily those of the editors or of the Japanese Circulation Society.

Received January 25, 2015; accepted January 26, 2015; released online February 10, 2015

Cardiovascular Division (T.I.), Department of Child Health (H.H.), Faculty of Medicine, University of Tsukuba, Tsukuba, Japan

Mailing address: Hitoshi Horigome, MD, PhD, Department of Child Health, Faculty of Medicine, University of Tsukuba, 1-1-1 Tennodai,

Tsukuba 305-8575, Japan. E-mail: hhorigom@md.tsukuba.ac.jp

ISSN-1346-9843 doi:10.1253/circj.CJ-15-0105

All rights are reserved to the Japanese Circulation Society. For permissions, please e-mail: cj@j-circ.or.jp 


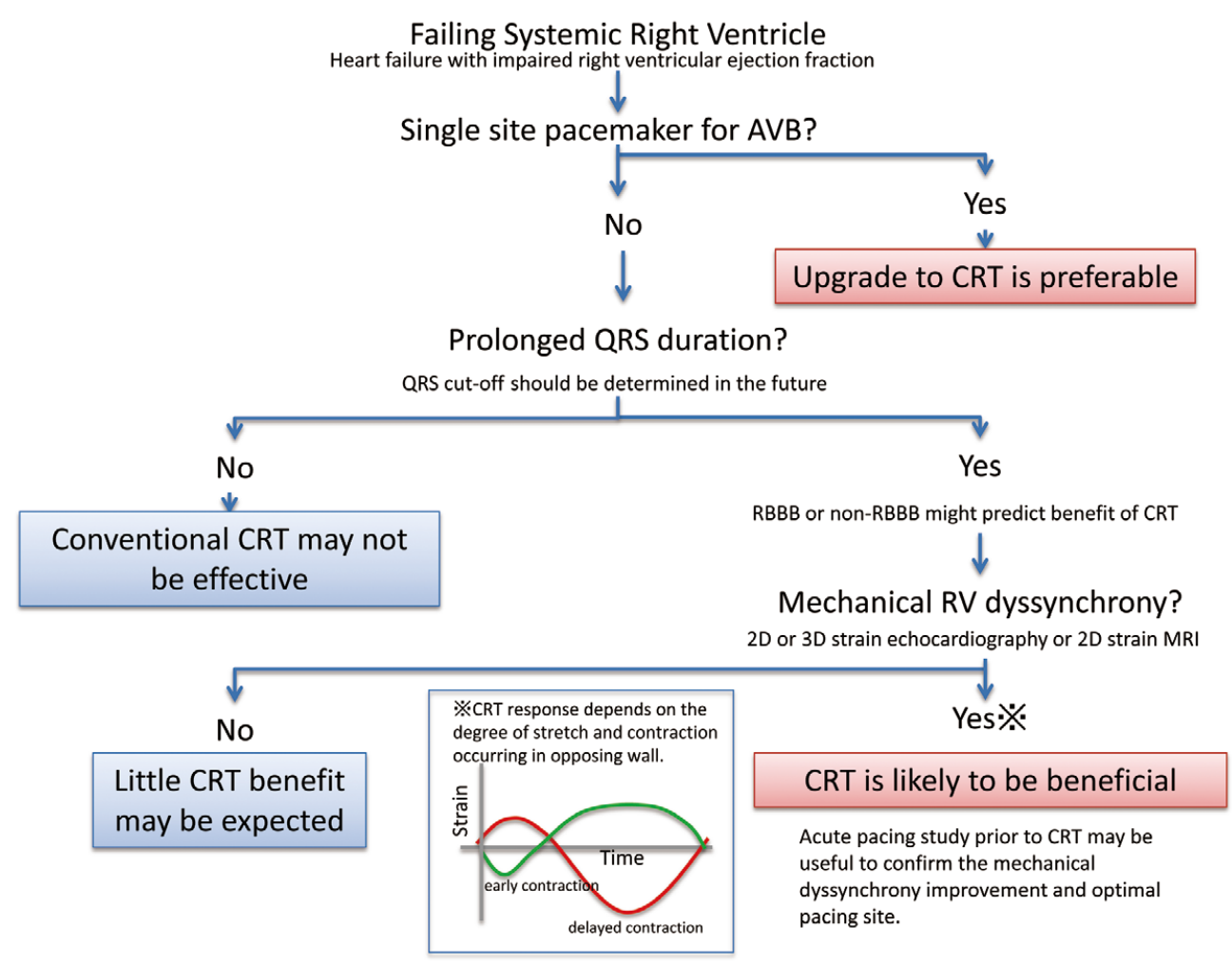

Figure 2. Flow chart of possible cardiac resynchronization therapy (CRT) implantation strategy in patients with systemic right ventricular failure. Assessment of mechanical dyssynchrony, QRS duration, and QRS morphology are extrapolated from the evidence of adult heart failure CRT trials. AVB, atrioventricular block; RBBB, right bundle branch block.

either the mean right ventricular ejection fraction (RVEF) or end-diastolic volume index.

\section{Article p 649}

\section{CRT for the Failing Systemic RV}

There have been mixed results of CRT for patients with a systemic RV. ${ }^{2}$ According to 3 multicenter retrospective cohorts, response defined as NYHA improvement $\geq 1$ class or RVEF improvement was observed in only 2 of 9 patients $(22 \%),{ }^{3} 19$ of 27 patients (79\%), ${ }^{4}$ and NYHA improvement was observed in 13 of 17 patients (76\%)..$^{5}$ Even in the study reporting a relatively good response, ${ }^{4}$ the response rate was significantly less than that of systemic left ventricule (LV) patients. Therefore, the study results imply that a detailed evaluation prior to CRT implantation may be crucial to identify who will benefit from CRT, especially for patients with systemic RVs.

\section{Assessment of RV Electrical Dyssynchrony}

There is currently no consensus for CRT indication in congenital heart disease patients. Adult heart failure guidelines are based on evidence from prospective randomized control trials including several thousands of participants. ${ }^{6}$ According to those guidelines, CRT is recommended as class I with level of evidence A, if the patient has LV ejection fraction $\leq 35 \%$, QRS duration $\geq 150 \mathrm{~ms}$ with left bundle branch block morphology, and NYHA class III-IV despite optimal medical therapy. In the adult population, right bundle branch block (RBBB) morphology (with systemic LV) is generally thought to confer smaller benefit of CRT. ${ }^{7}$ There has been no consensus on whether the CRT recommendation applies to systemic RV and wide QRS duration with RBBB morphology or not.

Based on the principles of CRT, biventricular pacing modifies intrinsic electrical dyssynchrony with prolonged QRS duration. This view is supported by the fact that CRT may have adverse effects in patients with a narrow QRS $(\leq 130 \mathrm{~ms})$, even when there is mechanical dyssynchrony. ${ }^{8}$ Therefore, the presence of electrical delay must be the essential requirement for CRT to be beneficial. Three-dimensional electrical activation contact mapping of the RV has reported the RBBB results in $\mathrm{RV}$ electrical dyssynchrony ${ }^{9}$ and may provide detailed understanding of systemic RV electrical propagation. ${ }^{10}$

\section{Assessment of RV Mechanical Dyssynchrony}

As mentioned, only prolonged QRS duration and the ECG morphology are the principles defining the CRT guideline in adult cardiology, because mechanical dyssynchrony assessed by conventional echocardiography has been concluded "as useless" by a multicenter trial. ${ }^{6}$ However, in the complex anatomy in congenital heart disease, surface ECG findings might not be accurate enough to identify CRT responders. Thus, cardiac imaging of mechanical dyssynchrony ${ }^{11}$ may improve selection of congenital heart disease patients who will benefit from CRT. Echocardiography is the most promising noninvasive imaging modality to evaluate mechanical dyssynchrony. ${ }^{12}$ Eyeball assessment of the presence of the septal flash or 
shuffle motion has been reported as a simple technique and strongly predictive for CRT response; ${ }^{13}$ however, Sakaguchi et $\mathrm{al}^{1}$ confirmed this movement in all patients characterized as non-responder. Recently, 2D ${ }^{14}$ and 3D ${ }^{15}$ strain echocardiography has been focused on as an accurate method of assessing mechanical dyssynchrony. Based on the available evidence, a flow chart indicating the possible CRT strategy for systemic $\mathrm{RV}$ is proposed in Figure 2.

\section{Conclusions}

New cardiac imaging modalities for assessment of electrical and mechanical dyssynchrony are required to provide more detailed information on the CRT indication in each patient with systemic RV failure.

\section{References}

1. Sakaguchi H, Miyazaki A, Yamada O, Kagisaki K, Hoashi T, Ichikawa $\mathrm{H}$, et al. Cardiac resynchronization therapy for various systemic ventricular morphologies in patients with congenital heart disease. Circ J 2015; 79: 649-655.

2. Horigome H. Current status and future direction of cardiac resynchronization therapy for congenital heart disease and pediatric patients. Circ J 2014; 78: 1579-1581.

3. Cecchin F, Frangini PA, Brown DW, Fynn-Thompson F, Alexander ME, Triedman JK, et al. Cardiac resynchronization therapy (and multisite pacing) in pediatrics and congenital heart disease: Five years experience in a single institution. J Cardiovasc Electrophysiol 2009; 20: 58-65.

4. Janousek J, Gebauer RA, Abdul-Khaliq H, Turner M, Kornyei L, Grollmuss $\mathrm{O}$, et al. Cardiac resynchronisation therapy in paediatric and congenital heart disease: Differential effects in various anatomical and functional substrates. Heart 2009; 95: 1165-1171.

5. Dubin AM, Janousek J, Rhee E, Strieper MJ, Cecchin F, Law IH, et al. Resynchronization therapy in pediatric and congenital heart disease patients: An international multicenter study. J Am Coll Cardiol 2005; 46: 2277-2283.

6. Tracy CM, Epstein AE, Darbar D, DiMarco JP, Dunbar SB, Estes NA 3rd, et al. 2012 ACCF/AHA/HRS focused update of the 2008 guidelines for device-based therapy of cardiac rhythm abnormalities: A report of the American College of Cardiology Foundation/ American Heart Association Task Force on Practice Guidelines and the Heart Rhythm Society [corrected]. Circulation 2012; 126: $1784-$ 1800.

7. Auricchio A, Lumens J, Prinzen FW. Does cardiac resynchronization therapy benefit patients with right bundle branch block: Cardiac resynchronization therapy has a role in patients with right bundle branch block. Circ Arrhythm Electrophysiol 2014; 7: 532-542.

8. Ruschitzka F, Abraham WT, Singh JP, Bax JJ, Borer JS, Brugada J, et al. Cardiac-resynchronization therapy in heart failure with a narrow QRS complex. N Engl J Med 2013; 369: 1395-1405.

9. Fantoni C, Kawabata M, Massaro R, Regoli F, Raffa S, Arora V, et al. Right and left ventricular activation sequence in patients with heart failure and right bundle branch block: A detailed analysis using three-dimensional non-fluoroscopic electroanatomic mapping system. J Cardiovasc Electrophysiol 2005; 16: 112-119, discussion $120-121$.

10. Silva JN, Ghosh S, Bowman TM, Rhee EK, Woodard PK, Rudy Y. Cardiac resynchronization therapy in pediatric congenital heart disease: Insights from noninvasive electrocardiographic imaging. Heart Rhythm 2009; 6: 1178-1185.

11. Seo Y, Ito H, Nakatani S, Takami M, Naito S, Shiga T, et al. The role of echocardiography in predicting responders to cardiac resynchronization therapy. Circ J 2011; 75: 1156-1163.

12. van der Hulst AE, Delgado V, Blom NA, van de Veire NR, Schalij MJ, Bax JJ, et al. Cardiac resynchronization therapy in paediatric and congenital heart disease patients. Eur Heart J 2011; 32: 2236-2246.

13. Doltra A, Bijnens B, Tolosana JM, Borras R, Khatib M, Penela D, et al. Mechanical abnormalities detected with conventional echocardiography are associated with response and midterm survival in CRT. JACC Cardiovasc Imaging 2014; 7: 969-979.

14. Ichikawa K, Dohi K, Sugiura E, Sugimoto T, Takamura T, Ogihara $Y$, et al. Ventricular function and dyssynchrony quantified by speckle-tracking echocardiography in patients with acute and chronic right ventricular pressure overload. J Am Soc Echocardiogr 2013; 26: $483-492$.

15. Atsumi A, Ishizu T, Kameda Y, Yamamoto M, Harimura Y, Machino-Ohtsuka T, et al. Application of 3-dimensional speckle tracking imaging to the assessment of right ventricular regional deformation. Circ J 2013; 77: 1760-1768. 